\title{
Accidental Corrosive Acid Ingestion Resulting in Isolated Pyloric Stenosis: A Rare Phenomenon
}

\author{
Lovekesh Kumar ${ }^{1}$, Ashish Saxena ${ }^{2 *}$, Mahendra Singh ${ }^{3}$, Yuvraj Kolhe ${ }^{2}$, Snehal K Karande ${ }^{2}$ and Om Prakash Prasad ${ }^{2}$ \\ ${ }^{1}$ Dept. of Surgery, Maulana Azad Medical College, New Delhi, India \\ ${ }^{2}$ Dept. of Surgery, Hindu Rao Hospital, New Delhi, India \\ ${ }^{3}$ Dept. of Surgery, AIIMS, Jodhpur, India
}

\begin{abstract}
Accidental corrosive ingestion is a common occurrence in developing nations. In most of the cases these agents damage the oesophagus and stomach. Isolated injury of pylorus of stomach has a relatively low incidence. We report such a case of accidental ingestion of corrosive acid, which resulted in isolated stenosis of the pyloric antrum. The diagnosis was confirmed by Barium meal and endoscopy. The patient underwent gastro jejunostomy and recovered well after the surgery. A brief discussion of mechanism of corrosive injury, clinical features, investigations and management follows.
\end{abstract}

Keywords: Corrosive poisoning; Isolated pyloric stenosis; Barium meal; UGI endoscopy; Gastro jejunostomy

\section{Introduction}

Corrosive acid ingestion is a common source of morbidity in the developing world. The incident is especially higher in India due to unregulated sale of corrosive material in the market [1]. Children are particularly susceptible to the accidental exposure to such substances due to inadequate parental supervision and careless storing of these chemicals at homes [2]. Both acid and alkali when consumed, cause significant injury to the upper gastrointestinal tract. The extent of injury depends upon several factors such as nature of the offending agent, amount, concentration and duration of exposure [1]. Typically corrosive acid ingestion leads to local reaction, oesophageal damage and gastric injury in that order [3]. Isolated injury to the stomach resulting in pyloric stenosis is very rare, accounting to as little as $3.8 \%$ of all the cases of corrosive ingestion, as reported in literature [4]. We report such a case of corrosive acid poisoning that resulted in isolated pyloric stenosis, without any oesophageal damage necessitating a bypass procedure. A brief discussion upon clinical picture (Figures 1 and 2) investigations and management follows.

\section{Case Report}

An 11 year old girl child presented to us with the history of accidental corrosive ingestion 1 month back. She was admitted in a medical ward for 1 week and was managed conservatively. After discharge she was tolerating oral diet satisfactorily until 1 week back, when she started regurgitating the ingested food a few hours after intake. For the last 1 week she was having frequent episodes of vomiting, especially after food intake and was losing weight.

Upon arrival at the surgical facility she had an emaciated appearance. Abdomen was scaphoid with fullness appearing in epigastrium after food intake. Succussion splash was present and the stomach was found to be dilated upon ausculto percussion. However, no mass was palpable in epigastrium.

She underwent routine blood investigations which demonstrated anemia and hypoproteinemia. Barium meal study and upper GI endoscopy were undertaken which revealed the presence of pyloric stenosis. Oesophagus and proximal stomach were found to be normal in appearance.
A diagnosis of gastric outlet obstruction was made and patient was taken for a bypass procedure. Intra operatively gastric mucosa was found to be inflammed and pylorus was thickened with a narrowed lumen. A gastro jejunostomy was performed to bypass the obstruction. The patient made an uneventful recovery following the surgery. She was taking normal diet and gaining weight as noted during her last follow up visit.

\section{Discussion}

Corrosive injuries of upper gastrointestinal tract occur frequently in India. These result mostly from the ingestion of corrosive substances either accidentally or with suicidal intent. Hydrochloric acid is the most common cause of corrosive poisoning in India, due to its easy availability as a cheap toilet cleaner [5]. The oesophagus and the stomach bear the major brunt of injury. Almost one third of the cases develop cicatrization of the stomach [6].

Acids produce coagulative necrosis of the tissue, and form an eschar at the site of injury resulting in segmental or extensive stricture formation in the long run. In contrast alkalis produce penetrating or liquifactive necrosis [7]. Acid is more likely than alkali to impart injury to stomach [8]. The pathological process begins a few hours after corrosive ingestion in the form of small vessel thrombosis. It continues for one to two weeks beyond which bacterial infection along with inflammatory response and granulation tissue deposition dominates the pathological profile [9]. Healing process begins three weeks after the injury, leading to fibrosis and narrowing of lumen, ultimately resulting in stricture [10].

*Corresponding author: Ashish Saxena, Department of Surgery, Hindu Rao Hospital, New Delhi, India- 110007, Tel: +91 9654249322; E-mail: docashish4u@gmail.com

Received November 03, 2014; Accepted February 06, 2014; Published February 12, 2015

Citation: Kumar L, Saxena A, Singh M, Kolhe Y, Karande SK, et al. Accidental Corrosive Acid Ingestion Resulting in Isolated Pyloric Stenosis: A Rare Phenomenon. Journal of Surgery [Jurnalul de chirurgie] 2015; 11(2): 371-373 DOI: 10.7438/1584-9341-11-2-4

Copyright: $\odot 2015$ Kumar L, et al. This is an open-access article distributed under the terms of the Creative Commons Attribution License, which permits unrestricted use, distribution, and reproduction in any medium, provided the original author and source are credited. 


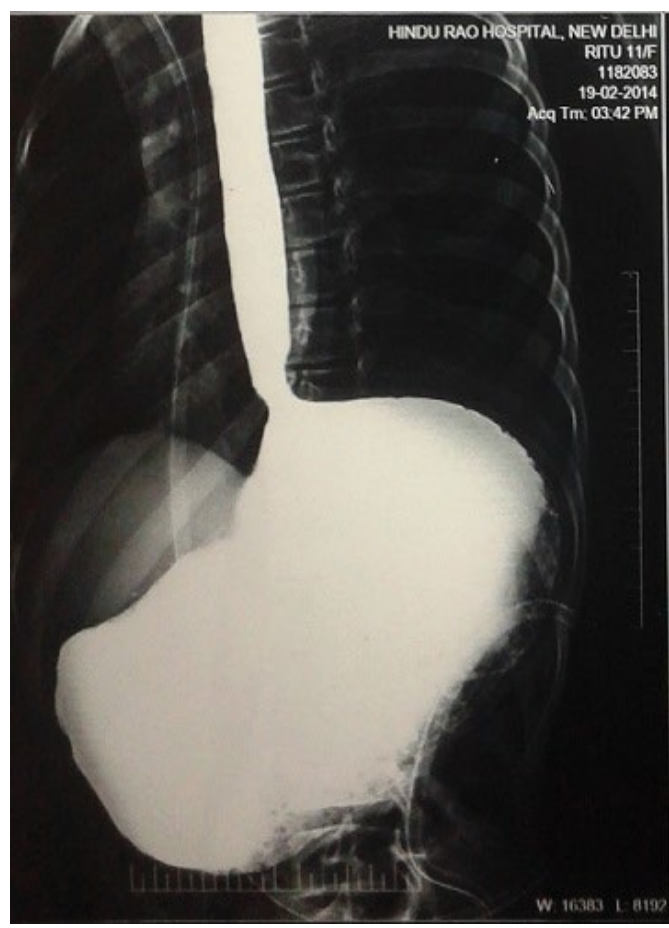

Figure 1: Barium meal study showing normal esophageal and gastric lining

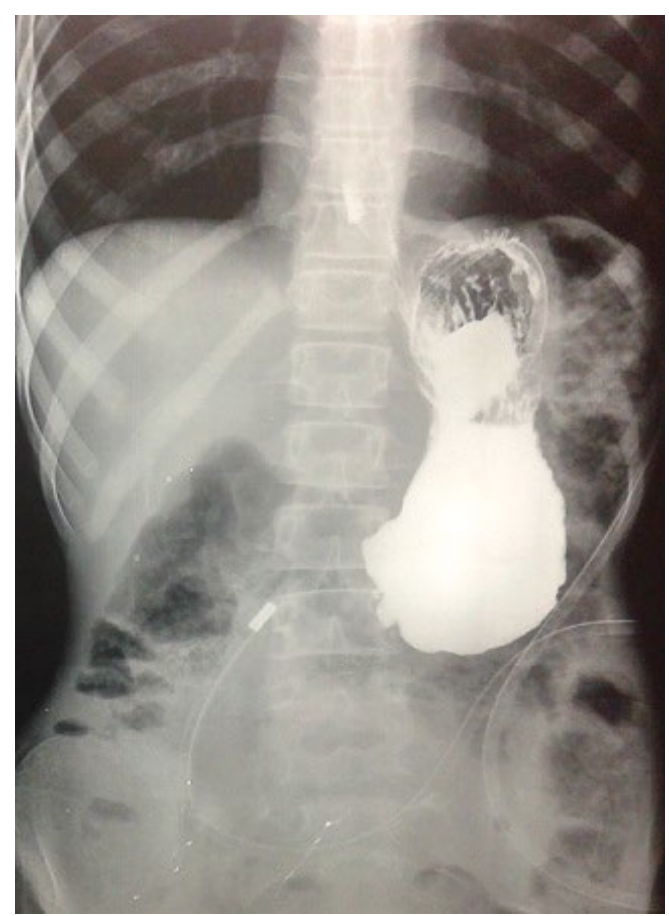

Figure 2: Barium meal study showing distended stomach with obstruction at pylorus Jejunostomy

Clinical features of the corrosive injury depend upon several factors such as nature; amount, concentration and duration of exposure of the offending agent [1]. The corrosives in powder and crystal form tend to adhere to the mouth and throat and produce maximum damage in these regions. The liquid agents pass rapidly through the esophagus and cause more damage to the sites of esophageal narrowing such as cricopharyngeal region, at the level of arch of aorta and lower esophageal sphincter [11].

The age old saying that "Acid licks the oesophagus and bites the stomach" still holds good [12]. Main reasons behind it being the relative resistance of oesophageal squamous epithelium to the acids, rapid passage through oesophagus, significant distensibility of stomach and acid induced reflex pyloric spasm. These factors prolong the contact period of acid with gastric mucosa and result in a myriad gastric deformity such as pyloric stenosis, antral stricture, hour glass stomach, or small contracted stomach [13]. In a study published by Ananthkrishnan et al., acid ingestion was found to be responsible for $82.6 \%$ of chronic gastric injuries, the majority of them constituted by pyloric stenosis [14].

Most of the patients with pyloric stenosis present within three months of ingestion of corrosive liquids, however symptoms are known to develop as late as one year after the injury [15]. These include feeling of fullness of stomach, nausea, and vomiting and weight loss, the features characteristic of gastric outlet obstruction (GOO). Associated features of GOO include severe dehydration and dyselectrolytemia.

Upon clinical examination fullness in the epigastrium is to be looked for, which is suggestive of underlying dilated stomach. Succusion splash and ausculto percussion are the hallmark clinical signs of GOO. Barium Meal and upper GI endoscopy constitute the radiological investigations required to establish the diagnosis. While a barium meal shows an over distended stomach with a narrowed pyloric lumen associated with delayed emptying, the endoscopy is vital in evaluating the mucosa of stomach and assessing the degree of lumen narrowing. The results of barium meal study and endoscopy determine the appropriate management.

The cases of partial obstruction can be managed by balloon dilation, endoscopic intra lesional steroid injection or pyloroplasty. On the other hand the complete gastric outlet obstruction is treated either by gastro jejunostomy or by gastric resection along with Bilroth I reconstruction [16]. As our patient was having complete obstruction of the pylorus she underwent gastro jejunostomy. Gastric resection was considered unsafe because of the presence of dense adhesions in the perigastric region.

\section{Conclusion}

Isolated pyloric stenosis following corrosive ingestion is a relatively uncommon entity. It is more frequently seen in the patients with acid ingestion. The features of gastric outlet obstruction manifest 3- 6 weeks after the ingestion of corrosive. Upper GI endoscopy and barium meal are the necessary investigations to establish the diagnosis. Surgical intervention in the form of pyloroplasty or gastro jejunostomy is the preferred treatment.

\section{References}

1. Lakshmi CP, Vijayhari R, Kate V, Ananthakrishnan N (2013) A hospital-based epidemiological study of corrosive alimentary injuries with particular reference to the Indian experience. Nat Med J India. 26: 31-36.

2. Urganci N, Usta M, Kalyoncu D, Demirel E (2014) Corrosive substance ingestion in children. Indian J Pediatr 81: 675-679.

3. Contini S, Scarpignato $C$ (2013) Caustic injury of the upper gastrointestinal tract: a comprehensive review. World J Gastroenterol 19: 3918-3930.

4. Ciftci, AO, Senocak ME, Buyukpamukcu N, Hiçsönmez A (1999) Gastric outlet obstruction due to corrosive ingestion: incidence and outcome. Pediatr Surg Int. 15: 88-91.

5. Agarwal S, Sikora SS, Kumar A, Saxena R, Kapoor VK (2004) Surgical management of corrosive strictures of stomach. Indian J Gastroenterol. 23: 178-180.

6. Zargar SA, Kochhar R, Nagi B, Mehta S, Mehta SK (1989) Ingestion of corrosive acids. Spectrum of injury to upper gastrointestinal tract and natural history. Gastroenterology 97: 702-707.

7. Chibishev A, Simonovska N, Shikole A (2010) Post-corrosive injuries of upper gastrointestinal tract. Prilozi 31: 297-316. 
8. Subbarao KS, Kakar AK, Chandrasekhar V, Ananthakrishnan N, Banerjee A (1988) Cicatrical gastric stenosis caused by corrosive ingestion. Aust N Z J Surg 58: 143-146.

9. Andreoni B, Biffi R, Padalino P, Marini A, Marzona L, et al. (1994) Artificial nutrition in the management of lesions caused by caustic ingestion. Chir Ital 46: 42-48.

10. Ionescu M, Tomulescu V, Gheorghe C, Popescu I (2000) [Post-caustic esophageal stenosis]. Chirurgia (Bucur) 95: 23-28.

11. Christesen HB (1993) Ingestion of caustic agents. Epidemiology, pathogenesis, course, complications and prognosis] Ugeskr Laeger 155: 2379-2382.
12. Marks IN, Bank S, Werbellof L, Farman J, Louw JH (1963) The natural history of corrosive gastritis: Report of five cases. Am J Dig Dis 8: 509-524.

13. Roy M Jr, Calonje MA, Mouton R (1962) Corrosive gastritis after formaldehyde ingestion: report of a case. N Engl J Med 266: 1248-1250.

14. Ananthakrishnan N, Parthasarathy G, Kate V (2010) Chronic corrosive injuries of the stomach-a single unit experience of 109 patients over thirty years. World J Surg 34: 758-764.

15. Hsu CP, Chen CY, Hsu NY, Hsia JY (1997) Surgical treatment and its longterm result for caustic-induced prepyloric obstruction. Eur J Surg 163: 275-279.

16. Poocharoen W (2008) Corrosive injury induced gastric outlet obstruction in children: A case report. Thai J Surg 29: 54-58. 